\title{
MODELLING OF DYNAMIC COMPLIANCE OF FIXTURE/WORKPIECE INTERFACE
}

\author{
Todorovic, P..; Vukelic, D.**; Tadic, B. ; Veljkovic, D. ; Budak, I.**; Macuzic, I. ${ }^{*} \&$ Lalic, B. ${ }^{* *}$ \\ ${ }^{*}$ University of Kragujevac, Faculty of Engineering, Sestre Janjic 6, 34000 Kragujevac, Serbia \\ ${ }^{* *}$ University of Novi Sad, Faculty of Technical Sciences, Trg Dositeja Obradovica 6, \\ 21000 Novi Sad, Serbia \\ E-Mail: petar@kg.ac.rs, vukelic@uns.ac.rs,btadic@kg.ac.rs, dveljkovic@kg.ac.rs,budaki@uns.ac.rs, \\ ivanm@kg.ac.rs, blalic@uns.ac.rs
}

\begin{abstract}
In this paper, the compliance of interface between fixture elements and workpiece is theoretically and experimentally investigated. The proposed theoretical model allows modelling of the behaviour of all kinds of interfaces between fixture elements and workpiece, under arbitrary dynamic loads. Workpiece displacement relative to fixture element was determined by analytical solution of the Lagrange differential equations of motion. Interface stiffness and damping coefficient were determined experimentally. The results of experimental investigation confirm the claims of theoretical model. (Received in April 2013, accepted in July 2013. This paper was with the authors 1 month for 1 revision.)
\end{abstract}

Key Words: Fixture, Modelling, Compliance, Stiffness, Damping, Dynamic Load

\section{INTRODUCTION}

One of the most critical features of a modern manufacturing system is the ability to design and produce lots of high-quality products in the shortest possible time. Due to stringent market demands and intensive development of science, and novel technologies, the trend of further development of machining processes depend on numerous factors. The factors which most influence quality of machining process are: type of blank, machining technology, operations, sub-operations, machine tools, cutting tools, fixtures, measuring devices, etc. [1]. In order to bring the machining process to a higher level, all these elements must be optimized.

During numerous machining processes, a workpiece must be properly located and clamped. Fixtures are devices which are used for quick and reliable workpiece locating and clamping, in a way which guarantees machining within the required tolerance. Fixtures are not only used for machining, but also for any other operation performed on a workpiece, e.g., welding [2], assembly [3], inspection [4], etc.

Fixtures directly influence machining costs. Costs related to fixture design and manufacture can amount to 10-20\% of the total manufacturing costs [5]. To shorten that time means also to decrease the adjoining costs. This can be done, among other things, by applying new methods in fixture design.

Numerous research efforts have been reported on the modelling of machining fixture under dynamic conditions. Meyer and Liou [6] presented a methodology to generate fixture layout under dynamic machining forces. Linear programming was used to determine optimal positions of locating elements and clamping forces. Wang et al. [7] developed an intelligent fixturing system to adjust the clamping forces adaptively to achieve minimum deformation of the workpiece according to cutting forces. Finite element analysis (FEA) was used to find the workpiece deformation. Liao and $\mathrm{Hu}$ [8] presented a system for fixture configuration analysis based on a dynamic model which analyses the fixture-workpiece system subject to timevarying machining loads. The influence of clamping placement was also investigated. Nee et 
al. [9] reported a sensor-assisted fixture that was capable of delivering varying clamping loads, calculated from a quasi-static model, to minimize workpiece distortion. Liao and $\mathrm{Hu}$ [10] developed a FEA-based model, which captures the dynamic compliance of the workpiece and the contact stiffness characteristics of the fixture-workpiece system. The model used instantaneous machining forces, in combination with FEA-extracted frequency response functions in order to predict the forced vibration amplitude of the workpiece. Melkote [11] presented a fixture layout and clamping force optimal synthesis approach that accounts for workpiece dynamics during machining. A combined fixture layout and clamping force optimization procedure was developed. He used the contact elasticity modelling method that accounts for the influence of workpiece in rigid body dynamics during machining. Hurtado and Melkote [12] formulated a multi-objective optimization model that defines minimum clamping loads to achieve workpiece shape conformability and fixture stiffness goals for a workpiece subjected to quasi-static machining forces. Kaya and Ozturk [13] simulated the machining operations by using a FEA model. The machining forces were considered as area force and applied over the tool workpiece contact area. Tan et al. [14] described the modelling, analysis and verification of optimal fixturing configurations by the methods of force closure, optimization and FEA modelling. Hamedi [15] presented a fixture design system which integrated nonlinear FEA into the artificial neural network (ANN) and genetic algorithm (GA). The GA-based program was used to search for the optimal value of clamping forces with small deformation/stress in the component. Deiab and Elbestawi [16] presented the results of a full factorial experimental investigation of the tribological conditions of the workpiece-fixture elements contact surface for workholding applications taking into consideration the effect of workpiece material, workpiece surface roughness, fixture element roughness, and normal load. Deng and Melkote [17] presented a model-based framework for determining the minimum required clamping force to ensure the dynamic stability of a fixtured workpiece during machining. Siebenaler and Melkote [18] presented a fixtureworkpiece model using FEA to investigate the influence of various parameters on workpiece deformation, including the compliance of the fixture body, contact friction, and mesh density. Ratchev et al. [19] addressed this knowledge gap by proposing a fixture-workpiece behaviour prediction methodology that utilized commercial FEA software for the prediction of complex fixture-workpiece behaviour during machining processes. Chen et al. [20] presented a fixture layout design and clamping force optimization procedure based on the GA and FEA. The optimization procedure was multi-objective: to minimize the maximum deformation of the machined surfaces and maximize the uniformity of deformation. Padmanaban et al. [21] used an ant colony algorithm (ACA)-based discrete optimization method to optimize fixture layout under dynamic conditions. They also proved that in the fixture layout optimization ACA outperformed GA. $\mathrm{Lu}$ et al. [22] created a cellular GA model of optimal clamping force determination as geometry and performance constrained multimodal function. Zuperl et al. [23] developed an intelligent fixturing system, adaptable to variable clamping forces to allow minimum workpiece elastic deformations based on cutter position and dynamic cutting forces. Vishnupriyan et al. [24] determined optimal fixture layout to minimize the machining error considering locator geometric error and workpiece elastic deformation. Chaari et al. [25] presented a modelling methodology for geometrical machining defect. The kinematical deviation due to part locating and relocating was modelled by homogeneous transformation. Dynamic displacements caused by clamping and machining force were determined by FEA. Vishnupriyan [26] investigated the significance of system compliance and workpiece dynamics as the two critical sources of machining error. Components of machining error were computed for different layouts and various clamping forces. Maracekova et al. [27] investigated effect of clamping pressure on workpiece inaccuracy in turning operations. They founded that the chucks clamping pressure induces elastic deformations and roundness 
deviation of workpiece. Vishnupriyan et al. [28] proposed a method of using an ANN for the prediction of dynamic workpiece motion. They optimized parameters of the ANN using a GA to achieve better prediction capability of the ANN and minimize different forms of errors in training and generalization. Liu et al. [29] developed geometric model considering the shape of a locator and a FEA-based force-deformation model. Based on these two models, multiple objects of fixture layout optimization problems were proposed, and a multiobjective GAbased optimization method was constructed. Selvakumar et al. [30] proposed a hybrid scheme to design an optimum fixture layout in order to reduce the maximum elastic deformation of the workpiece caused by the clamping and machining forces acting on the workpiece while machining.

Located and clamped in the fixture, workpiece is under dynamic loads during machining. Compliance of contact interface between workpiece and clamping elements during machining, greatly influences overall process quality. In this investigation, focus is placed on the modelling of dynamic compliance of fixture/workpiece interface. This topic is of special interest in cases when the increased interface load capacity is required under tangential dynamic loads, while the clamping forces must remain limited. This is often the case when machining thin-walled workpieces, especially when a single machining process is performed with numerous types of cutting tools.

In machining fixtures, cutting force is often partially balanced by the friction forces which occur at contact interfaces between workpiece and clamping elements [31]. In most of the cases, the disposition and magnitudes of cutting forces should be planned in such a way that no plastic deformations occur at contact surfaces of clamping elements workpiece [32]. However, there are a number of machining processes which allow a limited presence of plastic deformation on the workpiece, considering its functionality and aesthetic requirements. This is especially true for castings which, by recommendation, are clamped using coneshaped tips which cause plastic deformation within the clamping zone on the workpiece. According to previous investigations [33,34] clamping elements with cone-shaped tip exhibit some advantages over their spherical-tip counterparts regarding higher load capacity and lower interface compliance. Their investigations were performed under static loads and relatively large clamping forces. Within this investigation, the authors have considered theoretically and experimentally the advantages and problems of using clamping elements with cone-shaped tip in the domain of small clamping forces and dynamic contact interface loads. Moreover, for this specific type of clamping elements, stiffness and damping of the contact interface were calculated based on the theoretical and experimental investigations, which allowed us to model the workpiece dynamic behaviour under an arbitrarily set load function.

\section{THEORETICAL BACKGROUND}

A general case of contact between a clamping element and workpiece is considered (Fig. 1.). The clamping element, $K$, fixates the workpiece by the clamping force, $F_{n}$. In terms of materials, macro- and micro-geometry, there are various possible combinations of clamping elements and workpiece. Workpiece of mass, $m$, is loaded by cutting force, $F_{t}$, which acts tangentially, causing displacement of workpiece relative to clamping element, as defined by coordinate $\xi$. The magnitude of $\xi$ depends on numerous factors (macro- and micro-geometry of contact surface, materials of contact pairs, clamping force, $F_{n}$, tangential force, $F_{t}$, and other). The friction on surfaces $S_{1}$ and $S_{2}$ can be disregarded since only an isolated area of contact between clamping element and workpiece is being considered.

If a correlation (1) is determined experimentally using regression analysis for a specific type of contact interface: 


$$
F_{t}=\mathrm{f}\left(F_{n}, \xi\right)
$$

then it is possible, in principle, to determine the boundary displacement, $\xi$, at which - given the clamping force $F_{n}$ - the contact between clamping element and workpiece is maintained within the domain of elastic deformations. Let us assume that, for a range of clamping force values, $F_{n}$, and various contact interface features, relation (1) takes the form of a family of regression lines, as shown in Fig. 2. Then, values $\xi_{e 1}, \xi_{e 2}, \ldots, \xi_{e k}$ determine the boundaries of workpiece displacement within which the displacements still fall in the elastic deformation domain.

Interface stiffness can be calculated as:

$$
c=\frac{d F_{t}}{d \xi}=\frac{d f\left(F_{n}, \xi\right)}{d \xi}
$$

and under certain contact conditions and clamping forces, its value is constant.

Should the hypotheses be experimentally confirmed, it would mean that, for any type of contact interface, it is possible to establish the exact value of stiffness, $c$, which is valid over the domain of elastic displacements, as defined by $0 \leq \xi \leq \xi_{e}$.

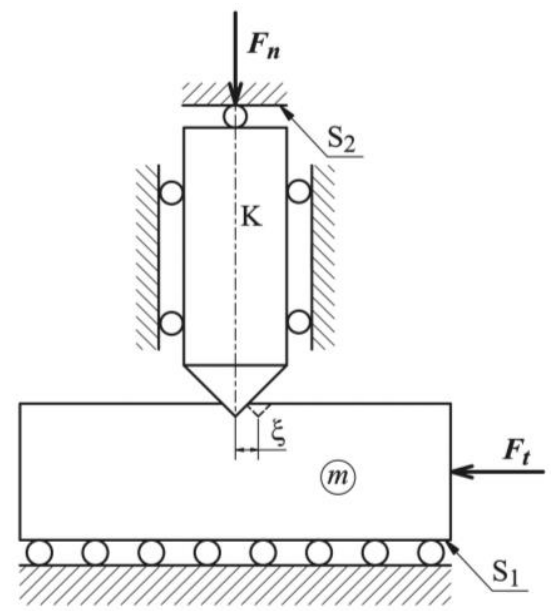

Figure 1: Schematic drawing of workpiece displacement relative to clamping element under tangential load.

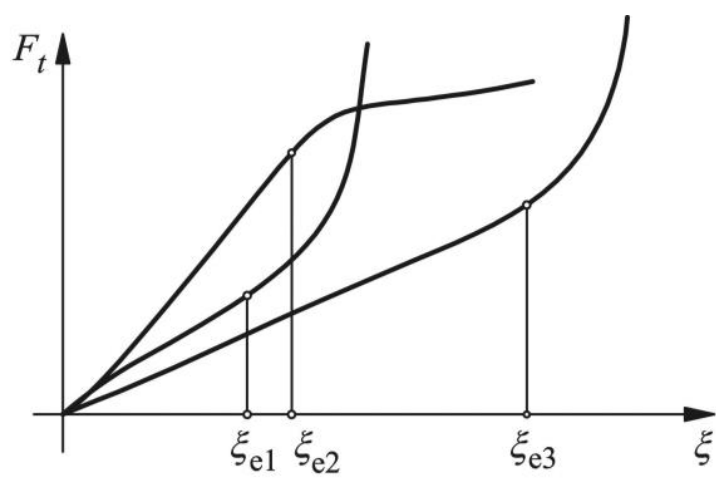

Figure 2: Theoretically derived curves which describe the dependence between workpiece displacement and tangential force.

Provided that the signals of tangential force, $F_{t}(t)$, and compliance, $\xi(t)$, are acquired as the functions of time under dynamic load regime, it is possible to determine the value of interface damping coefficient, $b$, from the following Lagrange differential equation of motion:

$$
m \cdot \frac{d^{2} \xi}{d t^{2}}+b \cdot \frac{d \xi}{d t}+c \cdot \xi=F_{t}(t)
$$

from which follows the equation for interface damping coefficient, $b$ :

$$
b=\frac{F_{t}(t)-m \cdot \frac{d^{2} \xi}{d t^{2}}-c \cdot \xi}{\frac{d \xi}{d t}}
$$

Once the stiffness, $c$, and interface damping coefficient, $b$, are established, it is possible to calculate workpiece displacement, $\xi(t)$, given the function of tangential force, $F_{t}(t)$, workpiece mass, $m$, and workpiece clamping force, $F_{n}$, by solving the differential equation for motion (3), i.e., by knowing the theoretical solutions of the Lagrange differential equation. 
It should be noted that in this case the equation solutions are valid over the range of $0 \leq \xi \leq \xi_{e}$ and within the range of clamping forces as used in determination of the regression function, $F_{t}=\mathrm{f}\left(F_{n}, \xi\right)$.

It means that, for an arbitrary clamping point, the contact interface between clamping elements and workpiece can be analyzed using the dynamic model shown in Fig. 3, i.e., using the well known theoretical solutions of Lagrange differential equation of motion.

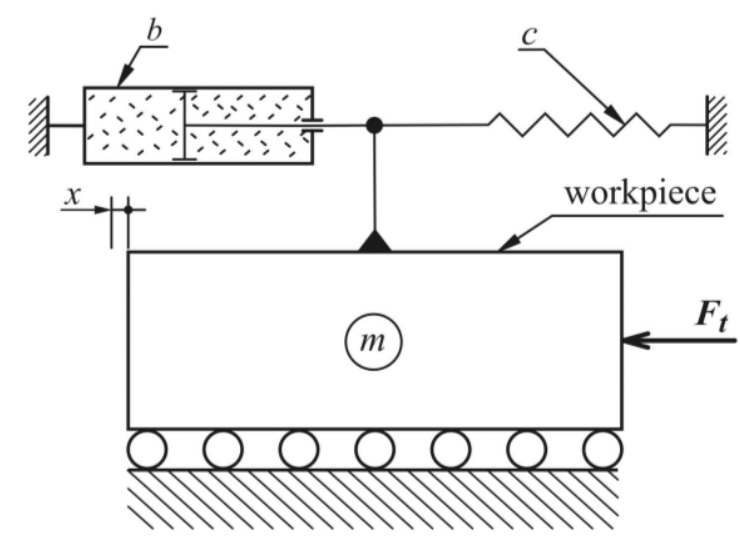

Figure 3: Schematic drawing of the dynamic model of contact interface between a clamping element and workpiece.

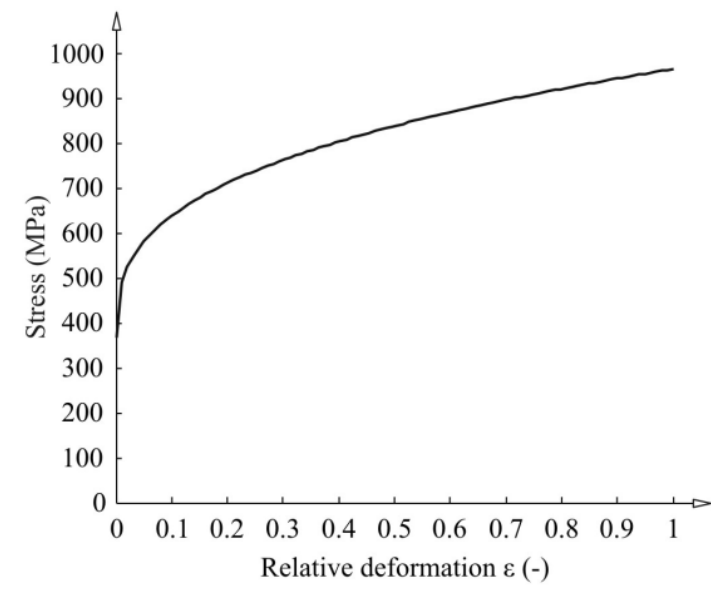

Figure 4: Strengthening curve for the tested material (C $45 \mathrm{E})$.

To substantiate the proposed theoretical model, some preliminary FEM analyses were made. Simufact Forming $v 9$ software was used to perform simulations of workpiece fixation with a cone-shaped clamping element and a small clamping force. Simulated was the clamping with a stiff clamping element with the $90^{\circ}$ cone angle, of tool steel material, HS 18 0-1, and 64 HRc hardness. Workpiece material was steel C $45 \mathrm{E}$, whose strengthening curve is shown in Fig. 4. Friction coefficient $\mu=0.15$ was adopted. The FEM model was meshed with $0.1 \mathrm{~mm}$ size hexahedral finite elements (FE), with the mesh being significantly refined in the contact interface area, where the FEs were of $0.025 \mathrm{~mm}$ size. The speed at which the clamping element performs indenting was set to $0.1 \mathrm{~mm} / \mathrm{s}$.

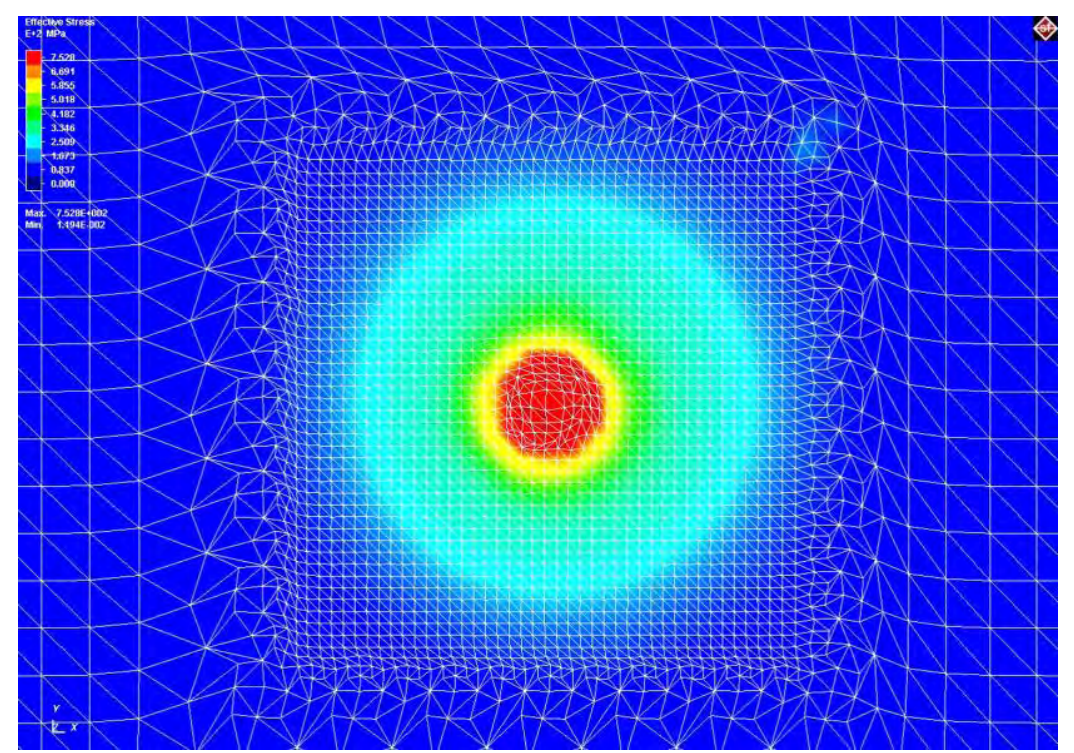

Figure 5: Distribution of stresses within the area of contact between the clamping element and workpiece. 
Steel C 45 E was the material used to represent workpiece specimens throughout experimental investigations performed in this study. FEM analyses were performed in order to gain insight into the stress field distribution within the narrow area of contact interface between workpiece and clamping element. Shown in Fig. 5 is the stress field distribution for the clamping force $F_{n}=510 \mathrm{~N}$. Such force magnitude causes the tip of the clamping element to penetrate workpiece material by $0.28 \mathrm{~mm}$.

Visible from Fig. 5 is that the stress magnitudes in the narrow contact area - at $F_{n}=510 \mathrm{~N}$ clamping force, which corresponds to $0.28 \mathrm{~mm}$ penetration of the clamping element tip - vary within the 418-752 $\mathrm{MPa}$ range. With this in mind, it is possible to assume that the stresses within the contact area - except in a very narrow pressure zone caused by the tip of the clamping element - do not significantly exceed the elastic deformation boundary, which is one of the basic assumptions of the previously proposed theoretical model.

\section{MEASURING EQUIPMENT}

Experimental investigations were performed using specially designed device [35]. Shown in Fig. 6 is the measuring system which consists of:

- The compression load cell FC2311-0000-0250, with force range up to $1100 \mathrm{~N}$, that measures tangential force, $F_{t}(t)$, which is proportional to cutting force;

- The inductive displacement sensor W1T, with nominal displacement of $\pm 1 \mathrm{~mm}$, and deviation of the sensitivity from normal sensitivity less than $\pm 1 \%$. Displacement transducer was calibrated prior to measurement on a tool microscope, UIM-21;

- The 2 channel HBM signal conditioner for load cell and inductive displacement sensor;

- The 8 analog input channels simultaneous sampling AD convertor with a 16-bit resolution, which was used for signal sampling from the load cell and inductive displacement sensor, and,

- The PC which controls the AD converter and stores the results of measurement for further processing.

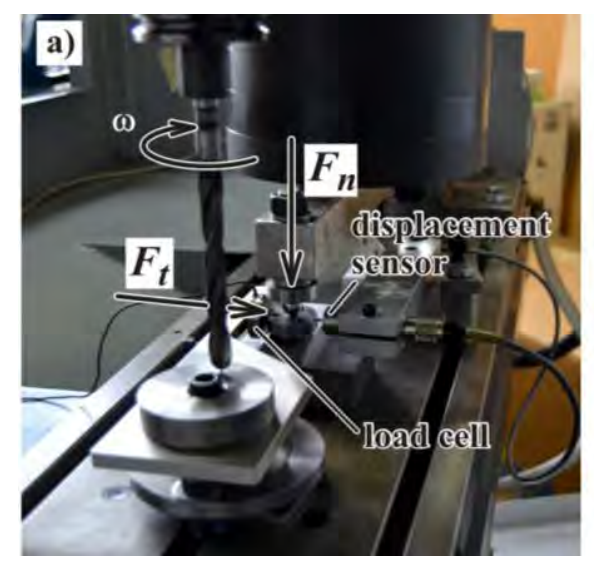

b)

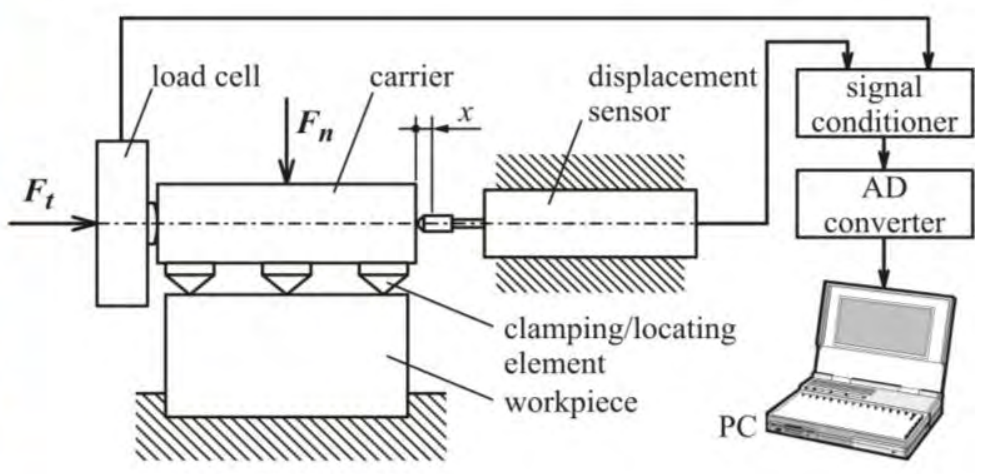

Figure 6: Measuring system, a) photo image, b) block diagram.

Tangential load of contact interface, $F_{t}$, is applied using realistic cutting force value. Normal load, $F_{n}$, (i.e. clamping force) is applied by the lever mechanism with calibrated weights and can be selected within a relatively wide value range. The specimens which represent locating elements, clamping element, and workpiece (Fig. 6 b) can be of various characteristics regarding macro-geometry, micro-geometry and material. This enabled comparison between various types of contact interfaces and their optimization from the aspect of minimizing interface compliance. 


\section{EXPERIMENTAL INVESTIGATION}

Model-based experiments were performed using specimens which represent a clamping element with a $90^{\circ}$ cone angle tip. Shown in Figs. $7 \mathrm{a}$ and $\mathrm{b}$ are photo images of the tested workpiece material and clamping element specimens. The cone-shaped clamping elements (Fig. 7 a) were made of tempered tool steel, HS 18-0-1, 64 HRC hardness. Both workpiece specimens and conical tips on clamping element specimens were grinded to surface finish of $R_{a}=0.8-1.0 \mu \mathrm{m}$. Workpiece specimens (Fig. $7 \mathrm{~b}$ ) were made of C $45 \mathrm{E}$ in annealed state.


Figure 7: Photo images of: a) clamping element specimen, b) workpiece specimens.

Clamping forces, $F_{n}$, were varied within the $395.8-631.2 \mathrm{~N}$ range. At each force value, several values of dynamic tangential force, $F_{t}$, were simulated by varying feeds of a twist drill, $\varnothing 12 \mathrm{~mm}$, at $n=600 \mathrm{RPM}$. The forces and the corresponding displacements were monitored and recorded using the previously described measuring system. Shown in Fig. 8 is an example of the tangential force, $F_{t}$, and the corresponding displacement, $\xi$. The signals of tangential force, $F_{t}$, and its corresponding displacement, $\xi$, obviously pertain to interface compliance within the elastic deformation domain, since the system returns to its initial state $(\xi \approx 0)$ upon cessation of the tangential force.

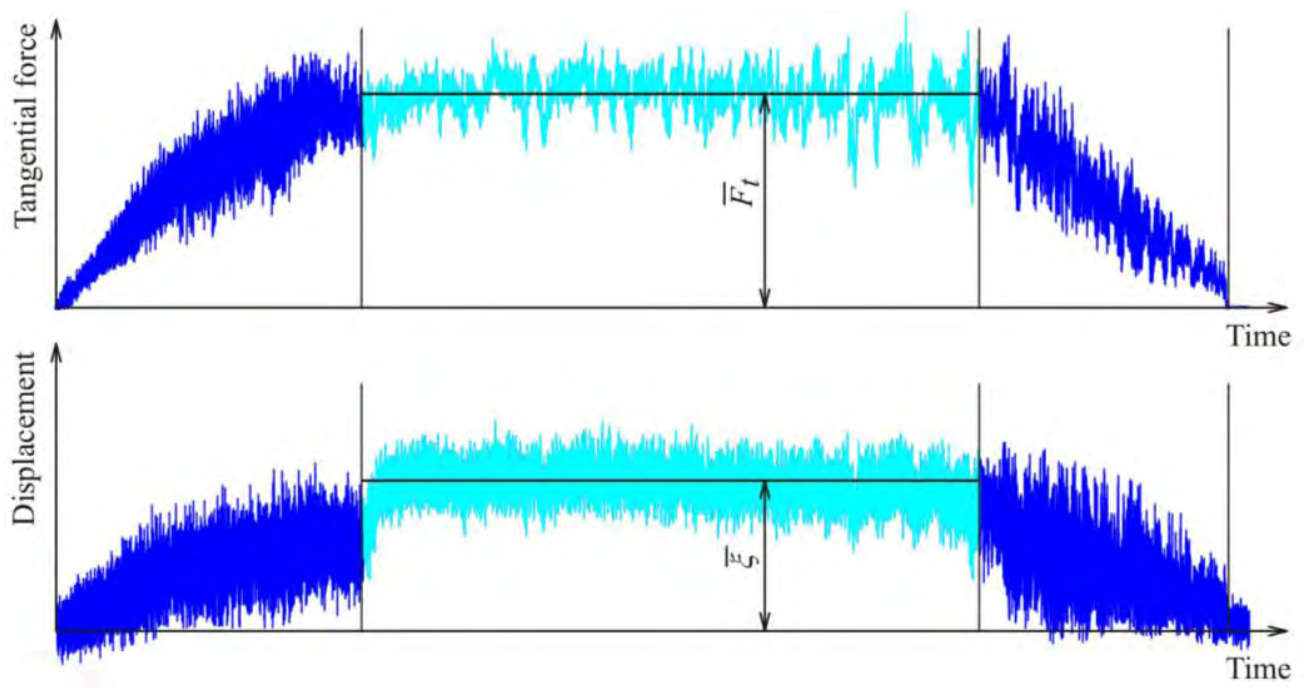

Figure 8: Recording of tangential force and corresponding displacement.

The processed results of measurement are shown in Table I. Table I lists the values of varied clamping forces, $F_{n}$, feed rate, $f$, mean dynamic tangential force, $\bar{F}_{t}$, and mean workpiece displacement, $\bar{\xi}$.

Fig. 9 shows the diagram of dependence between mean tangential load capacity of the tested contact interface, $\bar{F}_{t}$, on the mean workpiece displacement, $\bar{\xi}$, and clamping force, $F_{n}$. 
Table I: Measurement results showing mean cutting force values and mean displacement between clamping element and workpiece.

\begin{tabular}{|c|c|c|c|c|}
\cline { 2 - 5 } \multicolumn{1}{c|}{} & $F_{n}$ & $f$ & $\bar{F}_{t}$ & $\bar{\xi}$ \\
\hline No. & $(\mathrm{N})$ & $(\mathrm{mm} / \mathrm{min})$ & $(\mathrm{N})$ & $(\mu \mathrm{m})$ \\
\hline 1 & 631.2 & 20 & 27.51 & 3.19 \\
\hline 2 & 631.2 & 40 & 35.00 & 5.51 \\
\hline 3 & 631.2 & 60 & 50.88 & 3.28 \\
\hline 4 & 631.2 & 80 & 67.89 & 4.28 \\
\hline 5 & 631.2 & 100 & 83.46 & 5.04 \\
\hline 6 & 631.2 & 120 & 97.45 & 6.41 \\
\hline 7 & 631.2 & 140 & 109.47 & 6.49 \\
\hline 8 & 631.2 & 160 & 114.58 & 6.61 \\
\hline 9 & 513.5 & 20 & 22.09 & 1.73 \\
\hline 10 & 513.5 & 40 & 43.22 & 3.70 \\
\hline 11 & 513.5 & 60 & 58.13 & 5.44 \\
\hline 12 & 513.5 & 80 & 75.73 & 7.47 \\
\hline 13 & 513.5 & 100 & 90.48 & 10.08 \\
\hline 14 & 513.5 & 120 & 108.20 & 9.78 \\
\hline 15 & 513.5 & 140 & 109.74 & 9.51 \\
\hline 16 & 513.5 & 160 & 112.35 & 9.82 \\
\hline 17 & 395.8 & 20 & 29.44 & 3.01 \\
\hline 18 & 395.8 & 40 & 42.22 & 3.26 \\
\hline 19 & 395.8 & 60 & 63.04 & 4.61 \\
\hline 20 & 395.8 & 80 & 76.81 & 5.70 \\
\hline 21 & 395.8 & 100 & 85.91 & 6.46 \\
\hline 22 & 395.8 & 120 & 104.16 & 9.28 \\
\hline 23 & 395.8 & 140 & 105.38 & 8.31 \\
\hline & & & & \\
\hline
\end{tabular}

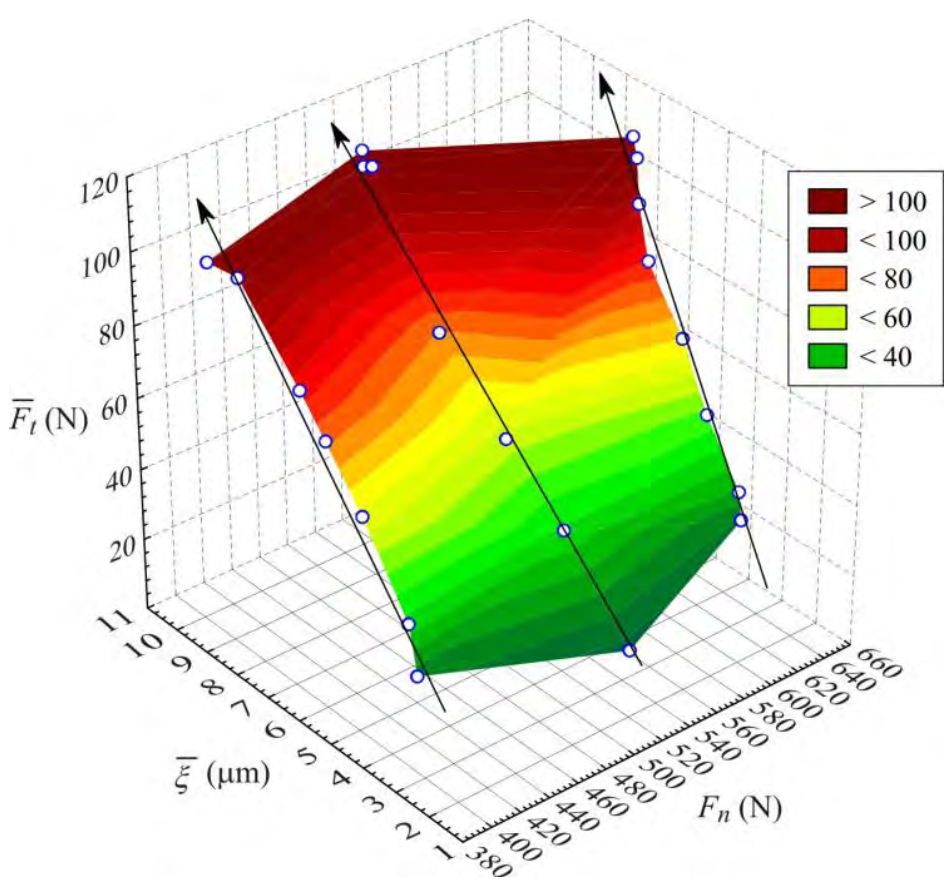

Figure 9: Diagram of dependence of the mean tangential load capacity on the mean workpiece displacement and clamping force obtained for the tested type of contact interface. 
Based on the change of $\bar{F}_{t}, \bar{\xi}$, and $F_{n}$, shown in diagram (Fig. 9), linear relationship is present between mean tangential force, $\bar{F}_{t}$, and mean displacement, $\bar{\xi}$, for the given value of clamping force, $F_{n}$, (indicated by arrows on the 3D diagram in Fig. 9). Through the data shown in Table I, a regression model was fitted in the following form:

$$
\bar{F}_{t}=\left(0.162 \cdot F_{n}-5.15668 \cdot 10^{-4} \cdot F_{n}^{2}+4.6889739 \cdot 10^{-7} \cdot F_{n}^{3}\right) \cdot \bar{\xi}
$$

with the regression coefficient of $R=0.95$.

Based on the theoretical considerations, the stiffness of contact interface equals:

$$
c=\frac{d \bar{F}_{t}}{d \bar{\xi}}=0.162 \cdot F_{n}-5.15668 \cdot 10^{-4} \cdot F_{n}^{2}+4.6889739 \cdot 10^{-7} F_{n}^{3}
$$

The unknown parameters were identified by non-linear Nelder-Mead optimization method [36], where in each step of the non-linear optimization, differential equation (4) was numerically integrated using Adams-Moulton method [37]. Thus it was established for all performed experiments, that the damping coefficient, $b$, and interface stiffness, $c$, range between $b=3.26-5.23 \mathrm{Ns} / \mu \mathrm{m}$, and $c=11.22-16.09 \mathrm{~N} / \mu \mathrm{m}$, respectively.

\section{DISCUSSION}

Based on the available literature, investigations related to analysis of dynamic behaviour of fixtures during machining are oriented in two directions. Majority of investigations are focused on analysis of dynamic behaviour of special fixtures. Although such investigations shed light on dynamic behaviour of fixture assembly, they do not provide an in-depth analysis of dynamic behaviour of a particular contact interface between clamping/locating element and workpiece. The other direction pertains to model-based investigations. Such investigations deal with interface load capacity and compliance of a particular type of contact interface, where the goal is to optimize micro-geometry of clamping of locating element in order to minimize fixture/workpiece interface compliance. Model-based investigations were performed at relatively large clamping forces under static tangential interface loads.

The results shown in this study belong to the model-based theoretical and experimental investigations of compliance/load capacity of fixture/workpiece interface under dynamic loads. Considering the present topicality of the thin-walled workpiece clamping, and the underlying theoretical considerations, the investigations were performed using relatively small clamping forces. The results of experimental investigations largely confirmed the initial theoretical claims. Namely, almost within the entire interval of the varied clamping forces, under the influence of tangential force, the displacements fell within the domain of elastic deformations, which is obvious from diagram in Fig. 9. In experiments under static loads [33], the clamping forces, $F_{n}$, have been varied within 313-16500 N interval. With this in mind, the dependence between tangential force and interface compliance takes the form of a typical material strengthening curve. However, investigation presented in this study featured much smaller clamping forces, which range from $395.8 \mathrm{~N}$ to $631.2 \mathrm{~N}$. Such magnitudes of clamping forces obviously correspond to predominantly elastic deformations - except in a very narrow pressure zone caused by the tip of the clamping element - which was confirmed by FEM analysis (Fig. 5). Based on regression equation (6) there follows that for the given range of clamping force values, the interface stiffness, $c$, is within the $11.22-16.09 \mathrm{~N} / \mu \mathrm{m}$ interval.

Confirmation of the proposed model, shown in Fig. 10, is an example of theoretical and experimental real-time dependence of workpiece displacement on the tangential force. Fig. 10 shows obvious correspondence between the theoretically derived workpiece displacement and the experimentally observed displacement. This fact enables us to apply solutions of Lagrange differential equation to analyze the dynamic behaviour of workpiece under the theoretically obtained dynamic load. The authors maintain that it is relatively easy to use the proposed 
model to investigate dynamic behaviour of a workpiece which is clamped over a larger number of arbitrarily chosen points using cone-shaped clamping elements.

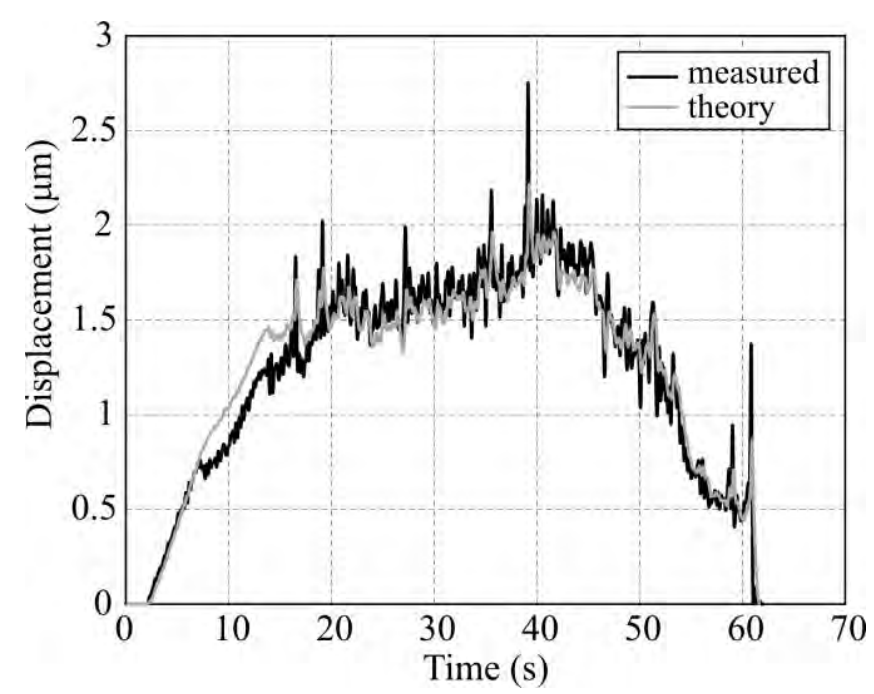

Figure 10: Theoretical and experimental dependence of real-time workpiece displacement on the tangential force (initial data: $m=0.083 \mathrm{~kg}, F_{n}=513.5 \mathrm{~N}, f=20 \mathrm{~mm} / \mathrm{min}$, derived values: $c=13.10 \mathrm{~N} / \mu \mathrm{m}, b=3.66 \mathrm{Ns} / \mu \mathrm{m})$.

\section{CONCLUSIONS}

The compliance of contact interface between clamping element and workpiece is directly connected with the machining error. The odds of larger machining errors occurring are especially high when a cutting force component acts normally to the clamping element axis. Such force component is usually balanced by the friction forces which occur between clamping elements and workpiece. Based on the literature review, one concludes that the clamping elements which use small, local plastic workpiece deformations, feature higher tangential load capacity compared to conventional spherical-tip clamping elements which have wide industrial use. It has been shown in this paper that, for a particular range of clamping forces, the cone-shaped clamping elements feature linear dependence between tangential loads and workpiece displacement relative to clamping element (indicated by arrows on the 3D diagram in Fig. 9), which confirms the theoretical considerations presented in this study. This allowed the authors to precisely define the stiffness of contact interface between clamping element and workpiece. The experimentally determined interface stiffness values and the damping coefficient for the particular contact interface type have provided theoretical background for the dynamic modelling of workpiece behaviour in fixture. Based on the model presented in this study it is possible to analyze dynamic behaviour of workpieces with varying mass, clamped over an arbitrary number of points. It should be noted that in this study interface stiffness and damping coefficient values were determined for a particular combination of: clamping element type, clamping force interval, and workpiece material. However, determination of those values under different experimental conditions is a mere technical question. It is well known that, with the real fixture designs which are subjected to tangential force acting normally to the clamping axis, largest compliance is present within the area of contact between the workpiece/clamping element contact zone. With this in mind, during fixture design it is very important to perform dynamic analysis to investigate displacement of workpiece at the clamping points, for a range of dynamic cutting forces. The authors maintain that this study provides the theoretical and experimental basis for such type of fixture design. 


\section{REFERENCES}

[1] Simunovic, G.; Balic, J.; Saric, T.; Simunovic, K.; Lujic, R.; Svalina, I. (2010). Comparison of the technological time prediction models, Strojarstvo, Vol. 52, No. 2, 137-145

[2] Fratini, L.; Micari, F.; Buffa, G; Ruisi, V. F. (2010). A new fixture for FSW processes of titanium alloys, CIRP Annals - Manufacturing Technology, Vol. 59, No. 1, 271-274, doi:10.1016/j.cirp.2010.03.003

[3] Iacob, R.; Popescu, D.; Mitrouchev, P. (2012). Assembly/disassembly analysis and modeling techniques: A review, Strojniski Vestnik - Journal of Mechanical Engineering, Vol. 58, No. 11, 653-664, doi:10.5545/sv-jme.2011.183

[4] Acko, B.; McCarthy, M.; Haertig, F.; Buchmeister, B. (2012). Standards for testing freeform measurement capability of optical and tactile coordinate measuring machines, Measurement Science and Technology, Vol. 23, No. 9, 13 p., doi:10.1088/0957-0233/23/9/094013

[5] Bi, Z. M.; Zhang, W. J. (2001). Flexible fixture design and automation: Review, issues and future directions, International Journal of Production Research, Vol. 39, No. 13, 2867-2894, doi:10.1080/00207540110054579

[6] Meyer, R. T.; Liou, F. W. (1997). Fixture analysis under dynamic machining, International Journal of Production Research, Vol. 35, No. 5, 1471-1489, doi:10.1080/002075497195425

[7] Wang, Y. F.; Wong, Y. S.; Fuh, J. Y. H. (1999). Off-line modelling and planning of optimal clamping forces for an intelligent fixturing system, International Journal of Machine Tools and Manufacture, Vol. 39, No. 2, 253-271, doi:10.1016/S0890-6955(98)00026-1

[8] Liao, Y. J. G.; Hu, S. J. (2000). Flexible multibody dynamics based fixture-workpiece analysis model for fixturing stability, International Journal of Machine Tools and Manufacture, Vol. 40, No. 3, 343-362, doi:10.1016/S0890-6955(99)00067-X

[9] Nee, A. Y. C.; Kumar, A. S.; Tao, Z. J. (2000). An intelligent fixture with a dynamic clamping scheme, Proceedings of the Institution of Mechanical Engineers, Part B: Journal of Engineering Manufacture, Vol. 214, No. 3, 183-196, doi:10.1243/0954405001517577

[10] Liao, Y. G.; Hu, S. J. (2001). An integrated model of a fixture-workpiece system for surface quality prediction, International Journal of Advanced Manufacturing Technology, Vol. 17, No. 11, 810-818, doi:10.1007/s001700170108

[11] Li, B.; Melkote, S. N. (2001). Optimal fixture design accounting for the effect of workpiece dynamics, International Journal of Advanced Manufacturing Technology, Vol. 18, No. 10, 701707, doi:10.1007/PL00003951

[12] Hurtado, J. F.; Melkote, S. N. (2002). A model for synthesis of the fixturing configuration in pinarray type flexible machining fixtures, International Journal of Machine Tools and Manufacture, Vol. 42, No. 7, 837-849, doi:10.1016/S0890-6955(02)00009-3

[13] Kaya, N.; Ozturk, F. (2003). The application of chip removal and frictional contact analysis for workpiece-fixture layout verification, International Journal of Advanced Manufacturing Technology, Vol. 21, No. 6, 411-419, doi:10.1007/s001700300048

[14] Tan, E. Y. T.; Kumar, A. S.; Fuh, J. Y. H.; Nee, A. Y. C. (2004). Modeling, analysis and verification of optimal fixturing design, IEEE Transactions on Automation Science and Engineering, Vol. 1, No. 2, 121-132, doi:10.1109/TASE.2004.835601

[15] Hamedi, M. (2005). Intelligent fixture design through a hybrid system of artificial neural network and genetic algorithm, Artificial Intelligence Review, Vol. 23, No. 3, 295-311, doi:10.1007/ s10462-004-7187-z

[16] Deiab, I. M.; Elbestawi, M. A. (2005). Experimental determination of the friction coefficient on the workpiece-fixture contact surface in workholding applications, International Journal of Machine Tools and Manufacture, Vol. 45, No. 6, 705-712, doi:10.1016/j.ijmachtools.2004. $\underline{09.021}$

[17] Deng, H.; Melkote, S. N. (2006). Determination of minimum clamping forces for dynamically stable fixturing, International Journal of Machine Tools and Manufacture, Vol. 46, No. 7-8, 847857, doi:10.1016/j.ijmachtools.2005.07.040

[18] Siebenaler, S. P.; Melkote, S. N. (2006). Prediction of workpiece deformation in a fixture system using the finite element method, International Journal of Machine Tools and Manufacture, Vol. 46, No. 1,51-58, doi:10.1016/j.ijmachtools.2005.04.007 
[19] Ratchev, S.; Phuah, K.; Liu, S. (2007). FEA-based methodology for the prediction of part-fixture behaviour and its applications, Journal of Materials Processing Technology, Vol. 191, No. 1-3, 260-264, doi:10.1016/j.jmatprotec.2007.03.020

[20] Chen, W.; Ni, L.; Xue, J. (2008). Deformation control through fixture layout design and clamping force optimization, International Journal of Advanced Manufacturing Technology, Vol. 38, No. 9-10, 860-867, doi:10.1007/s00170-007-1153-2

[21] Padmanaban, K. P.; Prabhaharan, G. (2008). Dynamic analysis on optimal placement of fixturing elements using evolutionary techniques, International Journal of Production Research, Vol. 46, No. 15, 4177-4214, doi:10.1080/00207540601147297

[22] Lu, Y. M.; Qin, G. H.; Li, M. (2011). A cellular genetic algorithm based optimization of clamping forces for fixture design, Advanced Science Letters, Vol. 4, No. 6-7, 2342-2346, doi:10.1166/asl.2011.1389

[23] Zuperl, U.; Cus, F.; Vukelic, D. (2011). Variable clamping force control for an intelligent fixturing, Journal of Production Engineering, Vol. 14, No. 1, 19-22

[24] Vishnupriyan, S.; Majumder, M. C.; Ramachandran, K. P. (2011). Optimal fixture parameters considering locator errors, International Journal of Production Research, Vol. 49, No. 21, 63436361, doi:10.1080/00207543.2010.532167

[25] Chaari, R.; Abdennadher, M.; Louati, J.; Haddar, M. (2011). Modelling of the 3D machining geometric defects accounting for workpiece vibratory behaviour, International Journal of Simulation Modelling, Vol. 10, No. 2, 66-77, doi:10.2507/IJSIMM10(2)2.173

[26] Vishnupriyan, S. (2012). Effect of system compliance and workpiece dynamics on machining error, Assembly Automation, Vol. 32, No. 2, 175-184, doi:10.1108/01445151211212325

[27] Maracekova, M.; Zvoncan, M.; Gorog, A. (2012). Effect of clamping pressure on parts inaccuracy in turning, Tehnicki Vjesnik - Technical Gazette, Vol. 19, No. 3, 509-512

[28] Vishnupriyan, S.; Muruganandam, A.; Govindarajan, L. (2012). Prediction of workpiece dynamic motion using an optimized artificial neural network, Proceedings of the Institution of Mechanical Engineers, Part B: Journal of Engineering Manufacture, Vol. 226, No. 10, 1705-1716, doi:10.1177/0954405412457121

[29] Liu, Z.; Wang, M. Y.; Wang, K.; Mei, X. (2012). Multi-objective optimization design of a fixture layout considering locator displacement and force-deformation, International Journal of Advanced Manufacturing Technology, Vol. 67, No. 5-8, 1267-1279, doi:10.1007/s00170-012$\underline{4564-7}$

[30] Selvakumar, S.; Arulshri, K. P.; Padmanaban, K. P.; Sasikumar, K. S. K. (2013). Design and optimization of machining fixture layout using ANN and DOE, International Journal of Advanced Manufacturing Technology, Vol. 65, No. 9-12, 1573-1586, doi:10.1007/s00170-012$\underline{4281-2}$

[31] Barkallah, M.; Louati, J. \& Haddar, M. (2012). Evaluation of manufacturing tolerance using a statistical method and experimentation, International Journal of Simulation Modelling, Vol. 11, No. 1, 5-16, doi:10.2507/IJSIMM11(1)1.194

[32] Cardoso, P.; Davim, J. P. (2012). Micro milling of metallic materials - A brief overview, Transactions of FAMENA, Vol. 36, No. 2, 79-85

[33] Tadic, B.; Jeremic, B.; Todorovic, P.; Vukelic, D.; Proso, U.; Mandic, V.; Budak, I. (2012). Efficient workpiece clamping by indenting cone-shaped elements, International Journal of Precision Engineering and Manufacturing, Vol. 13, No. 10, 1725-1735, doi:10.1007/s12541$\underline{012-0227-8}$

[34] Vukelic, D.; Tadic, B.; Miljanic, D.; Budak, I.; Todorovic, P. M.; Randjelovic, S.; Jeremic, B. M. (2012). Novel workpiece clamping method for increased machining performance, Tehnicki Vjesnik - Technical Gazette, Vol. 19, No. 4, 837-846

[35] Tadic, B.; Vukelic, D.; Miljanic, D.; Bogdanovic, B.; Macuzic, I.; Budak, I.; Todorovic, P. (2014). Model testing of fixture-workpiece interface compliance in dynamic conditions, Journal of Manufacturing Systems, Vol. 33, No. 1, 76-83, doi:10.1016/j.jmsy.2013.05.004

[36] Bunday, D. B. (1984). Basic Optimization Methods, Edward Arnold Ltd., London

[37] Press, W. H.; Flannery, B. P.; Teukolsky, S. A.; Veterling, W. T. (1992). Numerical Recipes, $2^{\text {nd }}$ edition, Cambridge University Press, Cambridge 